\title{
STUDENT BARRIERS TO PROSPECTS OF ONLINE LEARNING IN VIETNAM IN THE CONTEXT OF COVID-19 PANDEMIC
}

\author{
Dao Thi Hong VAN \\ ORCID: 0000-0002-3111-6765 \\ English Department \\ FPT University \\ Can Tho City, VIETNAM \\ Ha Hoang Quoc THI \\ ORCID: 0000-0002-1262-7914 \\ School of Education \\ Can Tho University \\ Can Tho City, VIETNAM
}

Received: 09/09/2020 Accepted: 20/11/2020

\begin{abstract}
This study was conducted to investigate student barriers to the prospect of online learning in Vietnam, in the context of Covid-19 pandemic. This mixed-method study attracted the participation of 1165 students from twelve universities and nine high schools across thirteen provinces in the Mekong Delta. The findings revealed the additional three obstacles from the qualitative data analysis including (1) geographical features, (2) the economic status of Vietnamese people, and (3) Vietnamese culture and traditions in addition to the six groups of barriers being re-confirmed from Berge's framework (2005). The results of Binary Logistic Regression testified the negative impacts of obstacles in Learner Motivation, Cost and Access to the Internet, and Social Interaction on the prospects of online learning, though it is predicted to go farther in education in Vietnam in the future.
\end{abstract}

Keywords: Online learning prospects, online learning barriers, Covid-19 pandemic, impacts, influential factors.

\section{INTRODUCTION}

According to Nguyen (2020), online learning in Vietnam has been provided by some universities, but it is absent in general education. In another statement, he testified that the Ministry of Education and Training (MOET) in Vietnam has directed and guided the online implementation for both university and high school education since the last few years. As a fact of matter, a lot of institutions and high school have been applying online teaching at different levels in accordance with their own training purposes.

In the early of the year 2020, under the impact of the Covid-19 pandemic, UNESCO (2020)'s first release about the number of students out of school is approximately 290 million. In response to school closure, they call for the practice of online learning and open educational applications, which encouraged teachers to reach learners from a far distance to minimize the risk of educational disruption. To meet the call of UNESCO and join the educational mainstream worldwide in the context of pandemic, most universities in Vietnam in general, and the Mekong Delta in particular have switched to online learning temporarily. Vietnamese education has been trying to uphold the spirit: "Even if students have to stay off schools, their learning will not be interrupted." (Nguyen, 2020).

The idea of that research has arisen when there were a great number of different opinions from teachers and learners about compulsory online courses after the social distancing period. Predicting the future of online learning in the Mekong Delta is hoped to provide educators significant insights to have in time implementations for the local education. 


\section{LITERATURE REVIEW}

\section{The Overview of Online Learning}

Online learning was taken into research in different ways of definition. AlHamad et al. (2014) perceived online learning as the chance to stay home and study as an advantage. Dabbagh and Bannan-Ritland (2005) figured out the presence of teachers and students in physical classrooms in a fixed time with teachers' linear teaching method being replaced by online learning with its all dynamic, unbound, and the practice of diversity pedagogical active learning and learner-centered approach (Barker, 2003; Browne, 2005). In addition, other researchers judged online learning as the flexibility of the classes (Atack, 2003; Fish, 2016; Horspool \& Lange, 2012; Platt et al., 2014; Sargeant et al., 2004; Wyatt, 2005) the convenience with and without family issues and/or health problems (Dyrbye et al., 2009; Kokko et al., 2015), and also the proliferation and popularity (Landrum et al., 2020).

Standing on another perspective, Urdan et al. (2000) consistently defined the term "online learning" as webbased learning, Internet-based learning, virtual learning, cyber learning or net-based learning, also known as a subset of distance education. Basic manipulations of online learning courses were performed with the use of "text and graphic of the course, exercises, testing and record keeping" while the more complicated one involved in animations, simulations, audio and video sequences, peer and expert discussion group, online mentoring, link to material on a web and communication with corporate education records (Urdan et al., 2000 , p. 8). It was, therefore, clearly to understand that online learning focuses on both online learning content and the support of obvious technology to provide meaningful and successful lessons. Similarly, based on the proportion of online content delivered, Allen and Seaman (2007) provided the four main kinds of learning. Specifically, traditional learning perceived the absent contribution of content delivered $(0 \%)$, while Web-facilitated approach allows the percentage of 1 to $29 \%$ online content delivered; Blended or Hybrid learning is defined as the practice of 30 to $79 \%$ learning content being transferred online; and Online learning is with more than $80 \%$ of the learning process occurring virtually. Details could be found in Figure 1 below:

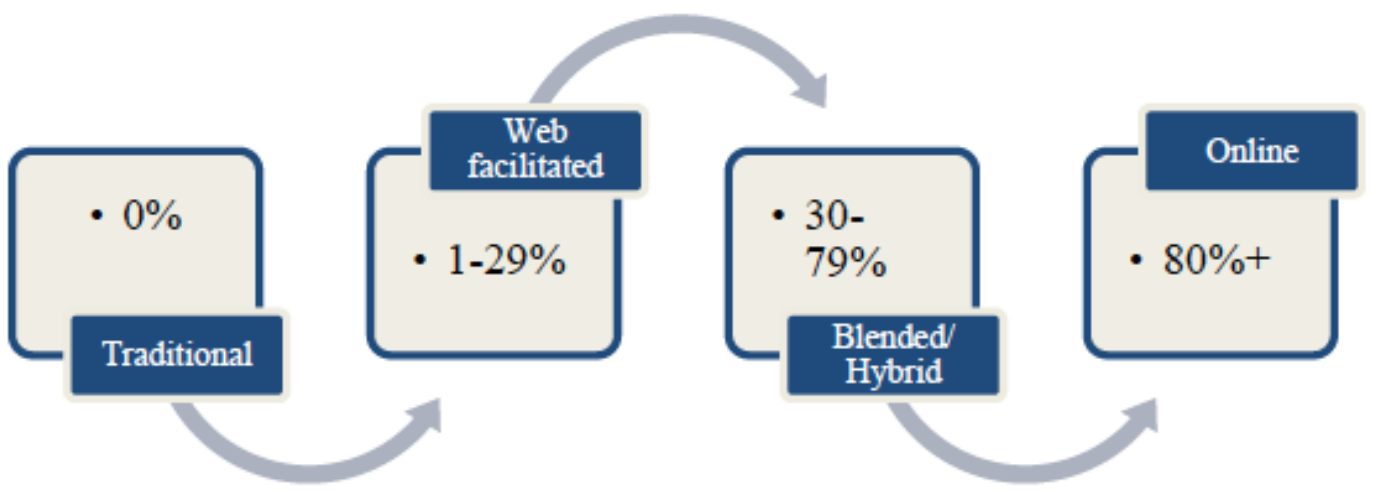

Figure 1. The proportion of online content delivered in different kinds of learning

Regarding online learning in higher education, Campbell (2004) argues the emphasis of online learning was on the metacognitive development of students such as reflexive and collaborative learning. Unplanned subject knowledge and learners' self-directedness, moreover, are hoped to be reached to optimize incidental learning and improve performance.

However, no good research has been done to investigate the best forms of online learning as well as what causes bad online pedagogy (Baggaley, 2014). Opposes of distance education or online learning have started for decades when considered as "digital diploma mills" (Noble, 1998) and the meaningless of schools without teachers (Moll, 1998). Baggaley (2014) emphasized that the teacher's role would not be degraded although online teaching has faced the reality of inconvenient truths, the massive student numbers and the inability 
of teachers. In addition, adapting face-to-face environments to online learning environments to evaluate the teaching quality and measure teaching effectiveness in a traditional way would be irrelevant to online teaching (Berk, 2013; Loveland \& Loveland, 2003; Lowenthal et al., 2015). There was a need for online learning to be evaluated particularly to this form of teaching (Lowenthal et al., 2015). Online courses were more favorable for qualitative and introductory courses (Comer et al., 2015). Comparing online and FTF classes, the prominent barriers involved in the quality of interaction among students in the classrooms (AlHamad et al., 2014; Dyrbye et al., 2009; Waldman et al., 2009) and the like from the instructors (Horspool \& Lange, 2012), the timeliness of responses (Boyd, 2008), and the uncertainty of students' work evaluation (Platt et al., 2014)ublisher $>$ Routledge $</$ publisher $><$ isbn $>0260-2938<$ isbn $><$ urls $><$ related-urls $><$ url $>$ https://doi. org/10.1080/02.

\section{Student Barriers to Online Learning in Different Contexts}

Barriers can be learned as the obstacles that hinder learners in acquiring their personal learning goals (Henderikx et al., 2019). Relying on geographical characteristics, kinds of learners, the local educational policies or the progress of technology in certain region, a wide range of studies has been done to investigate online learning' hindrance factors (Al-Senaidi et al., 2009; Ardichvili, 2008; Bacow et al., 2012; Barker, 2003; Browne, 2005; Dabbagh \& Bannan-Ritland, 2005; Fish, 2016; Henderikx et al., 2019; Horspool \& Lange, 2012; Khalil \& Ebner, 2014; Muilenburg \& Berge, 2005; Platt et al., 2014; Waldman et al., 2009). Henderikx et al. (2019) synthesized online learning barriers from previous studies as learners' difficulties in reading, writing, typing skills, technical problems with computers, feeling of isolation, family issues, interaction, lack of time, insufficient academic background, workplace issues and lack of support from family and friends or the workplace, insufficient technology background, computer and/or Internet issues, and lack of instructor presence. Furthermore, results from the empirical study of Henderikx et al. (2019) showed problems in students' own responsibility for learning, lack of time, bad course content, lack of motivation, low quality of instruction and/or family issues.

Muilenburg and Berge (2005) discovered eight different barriers as (1) social interaction, (2) administrative/ instructor issues, (3) time and supports for studies, (4) learners' motivation, (5) technical problems, (6) cost and access to the Internet, (7) Technical skills and (8) academic skills. Similarly, by naming the barriers from learners' perspectives, Ardichvili (2008) found different results as (1) interpersonal factors - e.g. fear of criticism and fear of misleading others; (2) procedural factors - i.e. lack of clarity on the best way of sharing, etc.; (3) Technological factors - i.e. lack of technological aptitude; and being different in other studies, the researcher had discovered the impact of (4) cultural factors - e.g. saving face, in-group orientation, etc.

By analyzing the views of the faculty or the participants with the teaching roles in distance learning, AlSenaidi et al. (2009) found various barriers including (1) Lack of equipment, (2) lack of institutional support, (3) disbelief of ICT benefit, (4) lack of confidence, and (5) lack of time. Interestingly, the study of Bacow et al. (2012) generated some distinct hinders as (1) the fear of losing their faculty rank, (2) the higher time investment to prepare for an online.

\section{Prospects of Online Learning}

"Prospects" in Marketing are used to refer potential customers. According to Klein (2004), "prospects" connotes the probability of success. Oxford dictionary also defines it as the possibility that something will happen. In this study the prospects of online learning are understood as the tendency of continuing online courses in the future. The most concern is whether students, especially the ones without prior experience in learning online before the Covid-19 pandemic, will volunteer to continue with future online courses or not. In a research of Mbuva (2014), online education was predicted to be grown "like a wild fire with no signs of quenching it", which attracted the concern of almost institutions, colleges to parents and students at different ages. 


\section{The Berge's Theoretical Framework (2005)}

On the basis of inheriting results of previous works (Garland, 1993; Muilenburg \& Berge, 2001; Schilke, 2001), the research was done in 2005 by Muilenburg and Berge with the aims of pointing out obstacles preventing online learning in the USA context. The questionnaire comprising 47 items was used as the instrument for quantitative research. The results after the main study accepted the deletion of the two unrelated issues. And the final of 45 items was adapted to be the instrument in our research. Details about the framework would be presented in Figure 2.

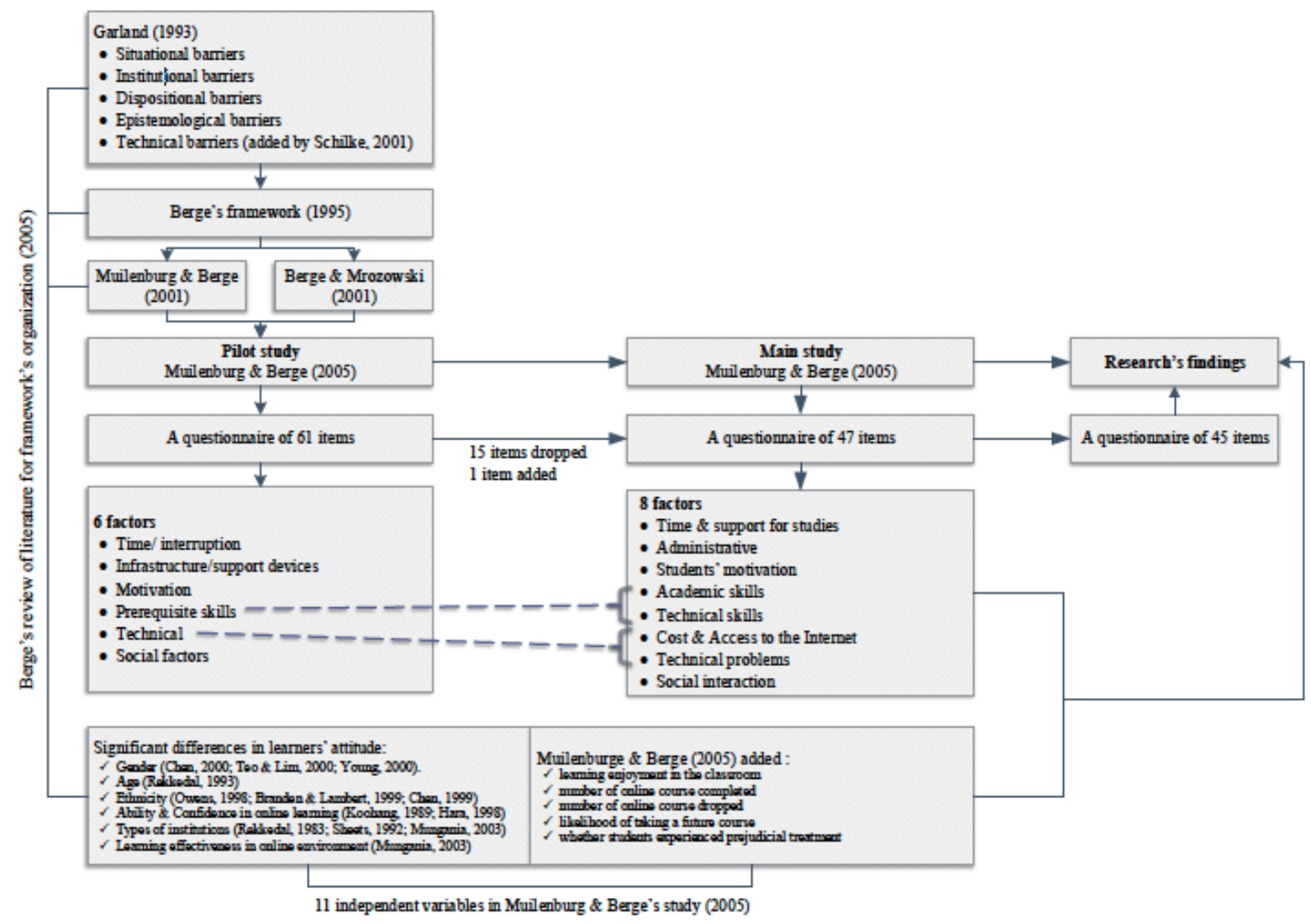

Figure 2. Berge's review of literature for framework (2005)

\section{RESEARCH METHODOLOGY}

According to Hurmerinta-Peltomaki and Nummela (2006), mixed-method approach gains a deeper and broader understanding of the phenomenon than study that is taken only with qualitative or quantitative approach. That integration also helps readers more confident in the findings and conclusion researchers draw in the studies (O'Cathain et al., 2010).

In this study, we firstly focus on barriers to the online learning process. An adaptation of Berge's framework (2005) is used to confirm online hindrance factors, with the support of Exploratory Factor Analyses. Then, we employed statistics on the percentage of students who answer will or will not take the future courses. By using Regression Binary Logistic, we would like to discover the correlation between perceived online learning barriers to their future decision. Also in this study, we wanted to go farther on learners' explanations for their extreme rating with any barriers. In search of finding new factors hindering the decision of continuing future online courses, the triangulation of both quantitative and qualitative results is hoped to provide an overview about the prospect of online learning and its obstacles during the time of Covid-19. The research model will be illustrated in Figure 3. 


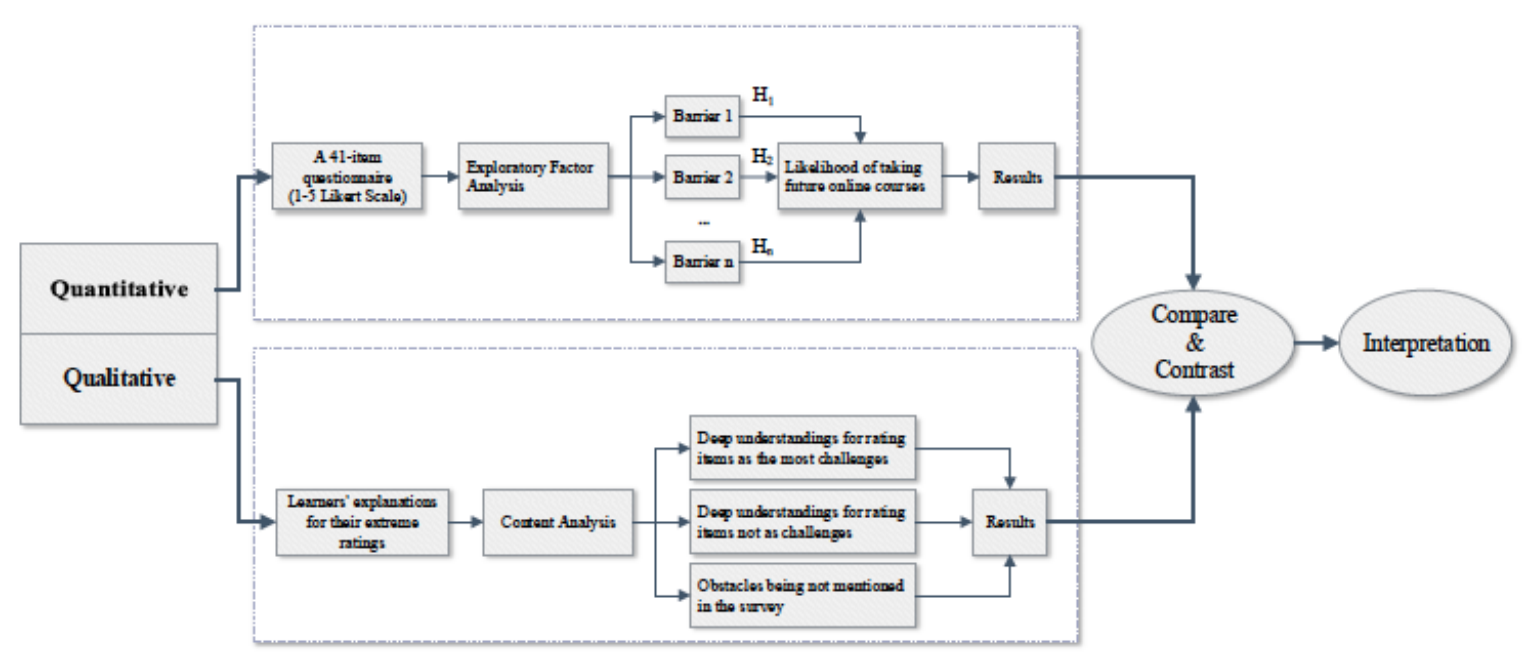

Figure 3. The research model

\section{Research Instrument - An Adaptation of Berge's Framework}

After considering the 45 items in the original version, which are all claims of barriers that students face while learning online, four items have been removed due to some certain reasons. Firstly, since participants in this study were all university and high school students aged from 16 to 25 years old, the item of "Fear family life will be disrupted" was deleted because of its inappropriateness. Furthermore, technical issues became predictable that most of the research has been discussed; we left our concern more on ranking other factors and looking for the new ones. Therefore, the three items were removed and Vietnamese version was generated to familiarize participants with the questionnaire. Participants were asked to rate each statement in accordance with their own reality while learning online on the 1-5 Likert Scale, ranging from "Completely agree" to "Completely disagree".

Cronbach Alpha was used to check the reliability of the 41-item questionnaire from Berge's adaptation (2005). Table 1 shows that all values are over 0.6 and the Correlated Item-Total Correlations are over 0.3. According to Nunnally and Bernstein (1994), the questionnaire is qualified to be studied in our context.

Table 1. Cronbach Alpha of each cluster in the questionnaire

\begin{tabular}{lcc}
\hline Clusters & Number of items & Cronbach Alpha \\
\hline Administrative/Instructors' issues & 11 & 0.89 \\
Social interaction & 06 & 0.86 \\
Academic skills & 06 & 0.91 \\
Technical skills & 06 & 0.92 \\
Learners' motivation & 05 & 0.77 \\
Time and support for study & 04 & 0.76 \\
Cost and access to the Internet & 03 & 0.80 \\
\hline
\end{tabular}

\section{Participants}

1221 online learners from more than twenty universities and high schools across thirteen provinces in the Mekong Delta joined in the survey. They were asked to respond the online Google Form from the end of April, 2020 to June 25, 2020. Data was selected carefully by removing fault or duplicated ones. The final of 1165 responses (95.4\%) were valid to be processed by using SPSS to give findings. Table 2 provides basic descriptions about participants of the study. 
Table 2. Descriptions of participants in the study ( $\mathrm{N}=1165)$.

\begin{tabular}{llll} 
& & $\mathrm{N}$ & $(\%)$ \\
\cline { 3 - 4 } Gender & Male & 454 & 39 \\
\multirow{3}{*}{ Level of education } & Female & 711 & 61 \\
& University & 794 & 68.2 \\
& High school & 371 & 31.8 \\
\hline
\end{tabular}

\section{FINDINGS}

This section firstly presented an overview of barriers that Vietnamese students face when learning online during the social distancing time of Covid-19 outbreak, by combining quantitative results from Exploratory Factor Analyses (EFA) and the qualitative findings of students' explanations for their extreme ratings. Secondly, we reported the prospects of online education in Vietnam under the impacts of those hindrance factors. Once again, quantitative results from Binary Logistic Regression and the qualitative ones from answers of open-ended questions were triangulated to give final results.

\section{An Overview of Online Learning's Barriers in Vietnam}

An EFA with Principal Axis Factoring extraction and Promax rotation was used in the study. This extraction method combining with Promax rotation reflects the data structure more exactly than that of Principal Components extraction (Gerbing \& Anderson, 1988). After removing disqualified items (these items being loaded into more than two groups with loading of 0.5 or greater), the remaining of 29 barriers to online learning (from the initial 41 ones) were loaded into six groups of barriers (see Table 4). Noticeably, all four items in the group of Time and Support for study were deleted after the processes, which cause the current study recorded the impacts of the six groups of factors, instead of seven as in the early stage. The factorability of the matrix was examined using the Kaiser-Meyer-Olkin Measure of Sampling Adequacy (KMO). In our study, KMO for the whole matrix was 0.937 . The initial eigenvalues were greater than 1 , which are considered significant. Bartlett's test has a significant level at 0.000 ; therefore, all variables are correlated. They were all accounted for $67.6 \%$ of the overall variance. According to Hair et al. (1998): “... in the social sciences, where information is often less precise, it is not uncommon to consider a solution that accounts for $60 \%$ of the total variance (and in some cases even less) as satisfactory" (p. 104). Some other hindrance factors discovered through the answers of open-ended questions are considered to provide deeper perspective about online learning barriers.

Table 3. Total variance explained

\begin{tabular}{lccc}
\hline & Initial Eigenvalues & & \\
\cline { 2 - 4 } Components & Total & \% of Variance & Cumulative \% \\
\hline Technical skills & 10.739 & 37.031 & 37.031 \\
Administrative/Instructors' issues & 2.850 & 9.829 & 46.860 \\
Social interaction & 1.911 & 6.590 & 53.451 \\
Academic skills & 1.648 & 5.681 & 59.132 \\
Cost and access to the Internet & 1.401 & 4.830 & 63.962 \\
Learners' motivation & 1.062 & 3.663 & 67.625 \\
\hline
\end{tabular}


Table 4. Pattern Matrix ${ }^{a}$

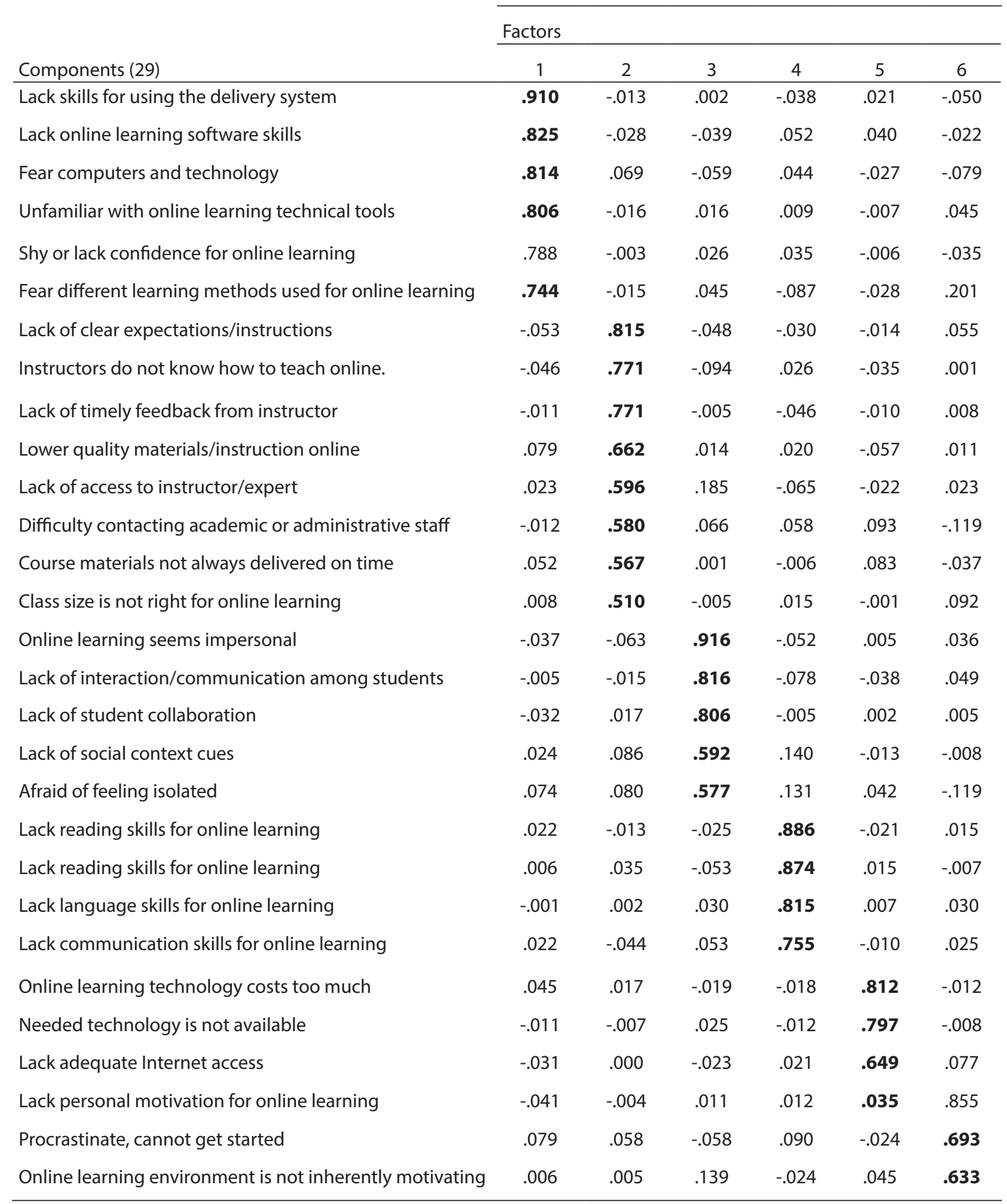

Extraction Method: Principal Axis Factoring. Rotation Method: Promax with Kaiser Normalization.

a. Rotation converged in 7 iterations. 
Table 5. Priority of student barriers to online learning

\begin{tabular}{lcc}
\hline Barriers factors $(\mathrm{N}=1165)$ & Mean & SD \\
\hline Cost and access to the Internet & 3.25 & 0.86 \\
Social interaction & 3.12 & 0.83 \\
Learners' motivation & 2.9 & 0.86 \\
Administrative and instructor's issue & 2.67 & 0.68 \\
Academic skills & 2.63 & 0.81 \\
Technical skills & 2.53 & 0.79 \\
\hline
\end{tabular}

Means of each factor were ranked to show the impact of these barriers on students' online learning. As presented in Table 5, the most influencing factors to Vietnamese students are problems about Cost and access to the Internet $(M=3.25)$. Social interaction and Learners' motivation closely stand for the next most challenges $(M=3.12$ and 2.9). Less severe barriers are Administration and instructor's issues and Academic skills $(M=2.67,2.63)$. Participants rated Technical skills as a very low challenge to their online learning $(M=2.53)$. Results gaining from text analysis provided learners' voice (with a total number of 170 students providing answers for open-ended questions, explaining their ratings) toward these groups of barriers as below.

\section{Cost and Access to the Internet}

All four items in this group received more approvals from participants. Twenty-three students mentioned the living conditions as impetuses or restraints of online learning occurrence. Other thirteen students admitted that they had no computers or laptops to study when they were in their hometown; their smartphones (if there were) were still not smart enough to run any online programs. Although this ratio was quite small in the general picture of online learning barriers, its existence would cause uncountable inconvenience for learners

Respondent \#476 just simply stated that "Economy is different from person to person", but it was strong enough to prove the hard condition that a part of students has been suffering. Respondents \#15, \#32, \#55, \#131 and \#256 had accepted their relative poor family status could not help them afford a private computer while they were learning in the college, and so was it at the time of pandemic, when money was much more of a challenge for them to earn.

For some students who have already had computers and laptops, the problems evolved in other perspectives such as using the available internet and the investment to set up the new ones or paying for 3G, 4G. Sixteen participants among 170 students giving answers for the open-ended questions said they were living in rural areas, where the Internet was still unpopular or they even did not have the Internet access. Respondents \#17 and \#114 shared the same ideas about the obligation of online learning which caused a lot of Internet problems. They had to pay a certain amount of money for it to be online promptly. Specifically, respondent \#461 complained about the additional fee for 3G but its access was not always strong as his expectation. Additionally, respondent \#1135 had to pay extra money to upgrade the Internet; and it would be worse when hearing the ideas from participant \#214, there were two classes that he had to pay 40 thousand VND each for $4 \mathrm{G}$ due to power outage, which is also the concern of 23 other participants since electricity in some regions is often interrupted.

Once these problems happen, online learning finds it hard to run as smoothly as it can. In Vietnam, especially in the Mekong Delta, almost all universities are situated in the city centers and when coming back to their hometown, students are unable to enjoy better learning conditions as they used to in their institutions. All in all, learning from a far distance with the help of the Internet seems to raise a big challenge for the one who lives in the countryside and also the ones who live in disadvantaged conditions. 


\section{Social Interaction Issues}

Most students agree that they prefer to learn in person. According to respondent \#369, face-to-face teaching and learning optimize the ability of interaction between the teacher and students, and among students as well; while such interactions become the most shortcoming of online learning. Seventy-three explanations were received from a hundred and seventy respondents (42.9\%) rating strongly agree with "Online learning lacks interaction among students." Respondents \#71, \#127, \#197, \#273 and other six respondents said virtual interaction via screens were extremely unnatural and easy to cause noises when lots of students wanted to discuss simultaneously. Respondent \#211 felt it hard to adapt to the new learning environment. From sharing of the twenty participants, switching on Internet-based courses were accused of pushing them into a blurred learning environment where they were unlikely to absorb knowledge as well as when they learned in traditional classes. Social interaction, under responders' discussion was also the reasons for students' senses of distraction (Respondents \#25, \#122, \#211, \#353, and \#407). As a result, difficulties caused by interaction drifted learners apart from online learning and gradually turned them back to traditional classrooms.

Some other students being in favor of online learning believed that interaction on cyberspace still took place normally as when they studied offline, though the reflections just occupied in cases.

\section{Learners' Voice toward Other Group of Barriers}

Learner motivation. As regards learner motivation factors, which are ranked in the third place $(\mathrm{M}=2.93$, $\mathrm{SD}=0.7$ ), especially with the statement "Must take more responsibility for learning". Among 170 responses from the open-ended questions, 30 students (17.6\%) mentioned "responsibility" in the connection with selfstudy, autonomy to raise their own attitude in learning, especially in the time of pandemic. Staying focused on learning without teachers' reminders and friends' discussion seemed to be hard, but it was their mission in the quarantine time (respondent \#860). Interestingly, with the item "Choose easier, less demanding aspects of assignments", a great number of participants $(\mathrm{n}=87)$ showed their strong reaction with their given online assignments. They totally admitted that they were asked to do a great deal of exercises with higher demand, which consequently caused them feelings of must-taking responsibility for their own learning. Respondent \#109 reassured himself "Given homework was more demanding as usual to help learners be steadier in their self-study period."

While respondent \#211 tiredly said: "Learning online requires students' high levels of self-study, extremely a lot. I just said the number of assignments is just from even to higher than the one when I learn offline." Similarly, "Assignment? I do not think it is simple enough. Just like and even more what we have to do in the traditional classroom.", said respondent \#475.

Administration and instructor's issues. 169 students strongly opposed the idea that teachers do not know how to teach online. Not many explanations were given for this issues, however, respondents \#203, \#808, \#926, and \#1079 all believed teachers had been trained in online teaching skills in advance and they knew how to select appropriate tools for teaching and learning. Respondent \#203 described his teachers' technological competence as adepts, or experts due to a wide range of teaching methods that he had experienced. A great deal of participants, on the other hand, provided more reasons why they did not approve "Low quality of materials/instructions online." 31 responders claimed that online materials were even more sufficient and more qualified than the printed ones, which were also transferred to students more quickly and economically.

"I completely disagree with that saying because when learning online, my teachers send me PowerPoint slides of the lessons. That makes me feel better than when I study offline, because sometimes I could not keep up with the lessons", said respondent \#22.

"About learning materials, it has a lot and a lot on the Internet. It is even more updated than offline materials.", said respondent \#273.

Time and Support for study. Aligning time-related obstacles, students agreed on keeping unchanged schedule for online classes benefited them from managing time for study (Respondents \#139, \#197, \#369, \#320 and the twelve others). Learning environment including family factors, neighborhood and other objective 
reasons like imposing sudden household activities while learning caused them lots of difficulties. Fourteen respondents reported in detail some situations they were requested for help by other family members; some revealed the negative impacts of noise from TVs, vehicles and daily sounds on their concentration. Respondent \#473 explaining much intervention occurred due to emergency cases from his families, loud music from his neighbors, Wi-Fi-lag, and power outage. Having an ethical mindset, respondents \#211 said: "...because we are living in Vietnamese family, where private learning zones are not really typical. I cannot stay focused on my lessons longer. Adults have rights in making all decisions for all things. For instance, when I was learning, I was asked to go grocery shopping, cleaning the house, and even banishing dogs out of the yard. They are extremely normal."

In addition to those students with disadvantaged learning conditions, some of the others $(\mathrm{n}=21)$ expressed their opposite situations where they were supported by their family physically and mentally. Respondent \#109 and \#1131 informed that they received the best support from their parents, which inspired them a lot in online learning.

Academic skills. Being similar to Administrative and instructor issues, Academic skills are not great challenges. 147 students (86.5\%) admitted that there seemed no discrepancies between learning online and offline; therefore, reading, writing, listening, communication skills and so on did not cause any problems. Just some cases revealed their difficulties in learning foreign languages like English, Korean, and Chinese. They were not confident enough since the imbalance between time to answer the question and their limitation in language proficiency (Respondent \#510, and \#450).

\section{Other Perceived Barriers from Answers of Open-Ended Questions}

The six groups of factors with 29 barriers (Table 3) have just accounted for $67.3 \%$ of the overall variance. Some other hindrance factors being discovered through the answers of open-ended questions are hoped to provide deeper understandings about online learning barriers.

Geographical issues. 20/170 students (11.8\%) giving the answer for the open-ended questions distinguished the words "city" and "countryside" to mention the disadvantaged conditions that prevented or hindered them in learning online. Vietnam is still a developing country and remote areas find it impossible to have the better Internet connection (Respondents \#177, \#10 and \#382). Sixteen participants said they were living in the rural areas, where Internet was still unpopular or they even did not have the Internet access. Especially in the time of Covid-19, respondents \#17 and \#114 shared the same ideas about the difficulties caused by the obligation of switching to online learning, including cost-related issues, electricity and distracting factors in their neighborhood.

The economic status of Vietnamese people. Due to the gap between rich and poor people in Vietnam, the rich can afford everything for their children while the poor cannot have enough conditions for laptops, smart phones, and the Internet. It caused a lot of difficulties when students were asked to switch to online learning due to Covid-19 pandemic. Thirteen students even said they had no technological devices to study online.

Family tradition and Vietnamese culture. Results found from the qualitative analysis showed that Vietnamese learners were dominated significantly by family factors. Being asked about the drop-out reasons from dropped-out participants, eighty-seven learners mentioned "family reasons" as an excuse for their escape. Thirty-two participants depicted the learning zone in their family as traditional designs of their houses, where people placed too much emphasis on common living space for the whole family members. As a consequence, learners had to suffer unexpected tasks while learning.

\section{Prospects of Online Learning and the Impact of Perceived Barriers}

A Binary Logistic Regression is constructed to identify the effect of these barriers on learners' decision to take future online courses. The dependent variable is students' decision (0- No, 1- Yes). The independent variables are the seven groups of barriers found from the result of EFA. They are (1) Cost and Access to the Internet, (2) Learner motivation, (3) Academic skills, (4) technical skills, (5) Administrative and instructors' issues, and (6) Social interaction. The 29 items constructing these factors were measured by 1-5 Likert scale, 
ranging from 1- Completely disagree to 5-Completely agree. Omnibus Tests of Model Coefficients is used to evaluate regression coefficient of independent variables. Table 6shows that sig of Step, Block and Model are 0.000 , lower than 0.05 so the regression model is statistically significant.

Table 6. Omnibus Tests of Model Coefficients

\begin{tabular}{lcccc}
\hline & & Chi-square & df & Sig. \\
\hline \multirow{2}{*}{ Step 1 } & Step & 297.985 & 6 & .000 \\
\cline { 2 - 5 } & Block & 297.985 & 6 & .000 \\
\cline { 2 - 5 } & Model & 297.985 & 6 & .000 \\
\hline
\end{tabular}

\section{Likelihood of Taking Future Online Courses}

When students are asked about the ability to take online courses in the future, with the two options Yes and No provided in the survey, the results show that 502 students (43.1\%) chose the "No" option, which means that they do not want to study online anymore. The remaining of 663 students (56.9\%) decided to continue taking future online learning. These numbers help to reflect a positive outlook for online learning in our context.

Table 7 also reveals the ability of taking and not taking future online courses based on two criteria: factual analysis and prediction. Specifically:

- Among 502 responders said they will not want to study online in the future, 324 of them are predicted not to take the future online courses, the percentage correct is $64.5 \%$.

- Among 663 responders said they will continue taking online courses in the future, 527 of them are predicted to take the future online courses. The percentage correct is $79.5 \%$.

- The percentage correct of the whole model is $73.0 \%$.

Table 7. Classification Table

\begin{tabular}{|c|c|c|c|c|c|}
\hline & & & \multicolumn{3}{|c|}{ Predicted } \\
\hline & & & \multicolumn{2}{|c|}{ Ability to take future online courses } & \multirow{2}{*}{$\begin{array}{l}\text { Percentage } \\
\text { Correct }\end{array}$} \\
\hline & & & No & Yes & \\
\hline \multirow{3}{*}{ Step 1} & \multirow{2}{*}{$\begin{array}{l}\text { Ability to take future } \\
\text { online courses }\end{array}$} & No & 324 & 178 & 64.5 \\
\hline & & Yes & 136 & 527 & 79.5 \\
\hline & Overall Percentage & & & & 73.0 \\
\hline
\end{tabular}

${ }^{*}$ Note. The cut value is .500

\section{The Correlation between Perceived Barriers and Prospects of Online Learning}

Table 8 reports the correlation of each group of barriers on the likelihood of taking future online courses. Figures for Sig of Wald of Social Interaction, Cost and Access to the Internet and Learner Motivation are lower than 0.05 . It can be concluded that these groups of factors have negative impacts on the likelihood of taking future online courses. Sig values of the others including Technical skills, Administrative and Instructors' issues and Academic skills are all above 0.05 and therefore, they are not statistically significant. Specifically, Learner motivation $(B=-.727)$ has the most impact on learners' decisions. It means that the lower motivation students have, the more impossibilities they get in taking future online courses. Similarly, Cost and Access to the Internet is ranked as the second most influential factor $(B=-706)$, followed by barriers in Social interaction $(\mathrm{B}=-519)$. 
Table 8. Variables in the Equation

\begin{tabular}{llcccccc}
\hline & B & S.E. & Wald & df & Sig. & Exp(B) \\
\hline Step 1a & Technical skills & -.127 & .116 & 1.213 & 1 & .271 & .880 \\
& Administrative and Instructors' issues & .233 & .130 & 3.218 & 1 & .073 & 1.263 \\
& Social interaction & -.519 & .111 & 21.910 & 1 & .000 & .595 \\
& Academic skills & .093 & .107 & .765 & 1 & .382 & 1.098 \\
& Cost and access to the Internet & -.706 & .097 & 53.400 & 1 & .000 & .493 \\
& Learner motivation & -.727 & .111 & 43.128 & 1 & .000 & .483 \\
\cline { 2 - 7 } & Constant & 5.856 & .448 & 171.059 & 1 & .000 & 349.194 \\
\hline
\end{tabular}

Note. Variable(s) entered on step 1: Technical skills, administrative and Instructor's issues, Social interaction, Academic skills, Cost and Access to the Internet, and Learner Motivation.

These correlations can be written as follows:

$\log _{\mathrm{e}}=\left(\mathrm{p}_{\mathrm{i}}\right.$ (likelihood in taking future online courses $\left.) / 1-\mathrm{p}_{\mathrm{i}}\right)=5.856-0.127 \mathrm{x}$ Technical skills $+0.233 \mathrm{x}$ Administrative and Instructors' issues -0.519 x Social interaction $+0.93 \times$ Academic skills $-0.706 \times$ Cost and access to the Internet $-0.727 \mathrm{x}$ Learner motivation

After removing variables with no significance in the study, the results after re-analysis can be presented as follows:

Table 8. Variables in the Equation

\begin{tabular}{llcccccc}
\hline & B & S.E. & Wald & df & Sig. & Exp(B) \\
\hline Step 1a & Social interaction & -.519 & .111 & 21.910 & 1 & .000 & .595 \\
& Cost and access to the Internet & -.706 & .097 & 53.400 & 1 & .000 & .493 \\
& Learner motivation & -.727 & .111 & 43.128 & 1 & .000 & .483 \\
& Constant & 5.856 & .448 & 171.059 & 1 & .000 & 349.194 \\
\hline
\end{tabular}

The binary regression equation is rewritten:

$\log _{\mathrm{e}}=\left(\mathrm{p}_{\mathrm{i}}\right.$ (likelihood in taking future online courses $\left.) / 1-\mathrm{p}_{\mathrm{i}}\right)=-0.519 \times$ Social interaction $-0.706 \times$ Cost and Access to the Internet -0.727 x Learner Motivation

\section{DISCUSSION AND CONCLUSION}

\section{The Consistency of Qualitative and Quantitative Findings}

Comparing the results of Table 3 about the priority of perceived barriers and Table 8 about the variables in the equation, a consistency could be found in the top of the three most extreme barriers and the top of the three most influential groups of barriers on the prospect of online learning. It means that when students found these challenges the most difficulties, these always have direct negative impacts on their future decision. Nevertheless, the group of Social interaction, Cost and access to the Internet, and Learner Motivation exchanged their position together. While being ranked as the third extreme barriers $(\mathrm{M}=2.9$, $\mathrm{SD}=0.86)$, Learner Motivation becomes the most influence of learners' decisions $(\mathrm{B}=-0.727)$. Cost and access to the Internet though causes the most difficulty for students $(\mathrm{M}=3.12, \mathrm{SD}=0.83)$, it does not mean they are the most hindrance factors for future online courses, they stood at the second position, right before the barriers in Social interaction $(\mathrm{B}=-0.706, \mathrm{~B}=-0.519)$. 
Possible explanations can be provided for other barriers, which have no impacts on the prospect of online education. Regarding technical skills, thirty-three students said computer knowledge became really basic nowadays and they did not see them as challenges. Respondents \#43, \#86, \#145, \#177, \#297, and \#824 believed technology was not their strengths, but they still knew how to study online. Respondent \#325 emphasized the fact that students were asked to learn Information Technology since grade 6 of the K-12 education. Some students were even skilled at Office, in addition to using some social networks like Zalo and Facebook. Moreover, a lot of tutorial videos on YouTube can help them solve any problems. These barriers could be surpassed if learners give them a try. Moreover, "before being asked to study online due to the Covid-19, students were trained how to use vital apps and platforms to study", respondent \#819 added. Being on a greater perspective, respondents \#824 and \#1022 saw online learning and high-end technology as modern issues and students, early or late, had to themselves update to join the future workforce.

\section{The Prospects of Online Education in Vietnam}

The findings indicated the prospects of online learning in Vietnam after the temporary education due to Covid-19, under the impacts of perceived barriers and some new factors discovered thanks to qualitative analysis. Specifically, together with the six groups of barriers being re-confirmed from Berge's study (2005), the other three new factors have been found including (1) geographical features, (2) economic status, and (3) Vietnamese culture and traditions. The results revealed a positive signal for online learning in Vietnam when receiving more students' supports, with 663 students' agreements (56.9\%) with future online courses. The results also reflected the negative impacts of the three groups of barriers on learners' decision. Diverse explanations were mined to gain insights reasons that hindered online learning practices.

As regards the two most extreme barriers including Cost and access to the Internet and Social interaction, the coincidence was compatible with the mainstream of Dyrbye et al. (2009), (Waldman et al., 2009)(Waldman et al., 2009), and AlHamad et al. (2014) about the interaction among students. The cost-related problems, which are not really barriers to other research context, however, become extreme in our study. Explanations for that result were somehow related to the formation of additional barriers from answers of open-ended questions, where students blamed for the distribution of low-quality Internet condition in rural areas and also the reasons from poor living conditions.

Besides, the family distraction was also found as a barrier in the research context. Unintentionally, it is partly compatible with Dyrbye et al. (2009) and Kokko et al. (2015) about the convenience with and without family issues and/or health problems. Together with the explanations of dropped-out students when learning online, a new barrier has been found related to Vietnamese tradition, where is famous with learning tradition, but students are also bombarded with chores easily and more importantly, family's reasons are repeated as the most frequent excuse.

\section{IMPLICATIONS}

Imposing online learning at the time of Covid-19 had caused both opportunities and challenges for Vietnamese students to simultaneously experience online education in predictable disadvantages. Although the development of technology has created favorable learning conditions, a lot of hindrance factors interrupted students' expectation to continue distance learning. Predicting future of online courses on the basis of analyzing the impacts of online learning barriers helps to evaluate Vietnamese learners' preferences and pose a series of action to optimize online learning and teaching's effectiveness, which also provides educators on time adjustment to help Vietnamese students flow in the mainstream of international education, where online education has been a trend. 


\section{BIODATA AND CONTACT ADDRESSES OF AUTHORS}

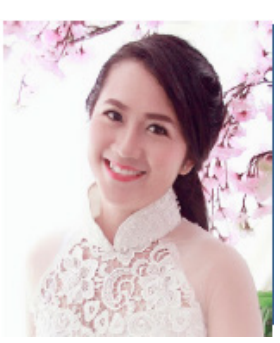

Dao Thi Hong VAN is an independent researcher in the Mekong Delta, Vietnam. She finished her Master degree in Principles and Methods in English Language Education. With a nearly ten-year teaching experience for students at different ages, she finds her strong teaching passion in every lesson, which urge herself to study on innovative teaching methods. She is especially eager to take part in international conferences and workshops. Her academic interest areas vary from distance education, to technologybased teaching techniques, English teaching methods, teaching career, and professional development.

Dao Thi Hong VAN

English Department, FPT University

Address: 600 Nguyen Van Cu Street, Can Tho City, 900000, Vietnam

Phone: +84977666400

E-mail: vandth10@fe.edu.vn

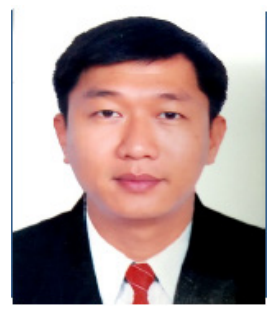

Ha Hoang Quoc THI is a lecturer in Information Technology in Can Tho University, Vietnam. He finished his Master degree in Data Mining in the University of Nantes, France. With 15+ years of teaching experience, he has joined in a lot of fields of research, especially integrating technology into teaching in different subjects. His research interest areas are not limited to his areas of expertise, but technology-based teaching techniques, and distance learning. He is also keen on partaking in international conferences and workshops.

Ha Hoang Quoc THI

School of Education, Can Tho University

Address: 3/2 Street, Can Tho City, 900000, Vietnam

Phone: +84977090919

E-mail: hhqthi@ctu.edu.vn

\section{REFERENCES}

Al-Senaidi, S., Lin, L., \& Poirot, J. (2009). Barriers to adopting technology for teaching and learning in Oman. Computers education, 53(3), 575-590. https://doi.org/10.1016/j.compedu.2009.03.015

AlHamad, A. Q., Al Qawasmi, K. I., \& AlHamad, A. Q. (2014). Key Factors in Determining Students' Satisfaction in Online Learning Based on'Web Programming'course within Zarqa University. International Journal of Global Business, 7(1), 7.

Allen, I. E., \& Seaman, J. (2007). Online nation: Five years of growth in online learning. ERIC.

Ardichvili, A. (2008). Learning and knowledge sharing in virtual communities of practice: Motivators, barriers, and enablers. Advances in developing human resources, 10(4), 541-554. https://doi. org/10.1177/1523422308319536

Atack, L. (2003). Becoming a web-based learner: registered nurses' experiences. Journal of advanced nursing, 44(3), 289-297. https://doi.org/10.1046/j.1365-2648.2003.02804.x

Bacow, L. S., Bowen, W. G., Guthrie, K. M., Long, M. P., \& Lack, K. A. (2012). Barriers to adoption of online learning systems in US higher education. Ithaka New York, NY. https://doi.org/10.18665/sr.22432

Baggaley, J. (2014). Online learning: a New Testament. Distance Education, 35(1), 133-140. https://doi.org $/ 10.1080 / 01587919.2014 .889589$

Barker, A. (2003). Faculty development for teaching online: Educational and technological issues. The Journal of Continuing Education in Nursing, 34(6), 273-278. https://doi.org/10.3928/0022-012420031101-10 
Berk, R. A. (2013). Face-to-face versus online course evaluations: A" consumer's guide" to seven strategies. Journal of Online Learning Teaching, 9(1), 140.

Boyd, P. W. (2008). Analyzing students' perceptions of their learning in online and hybrid first-year composition courses. Computers Composition, 25(2), 224-243. https://doi.org/10.1016/j. compcom.2008.01.002

Browne, E. (2005). Structural and pedagogic change in further and higher education: a case study approach. JournalofFurtherandHigherEducation, 29(1),49-59.https://doi.org/10.1080/03098770500037754

Campbell, L. (2004). What does the "e" stand for. Forest Ecology and Management.

Comer, D. R., Lenaghan, J. A., \& Sengupta, K. (2015). Factors that affect students' capacity to fulfill the role of online learner. Journal of Education for Business, 90(3), 145-155.

Dabbagh, N., \& Bannan-Ritland, B. (2005). Online learning: Concepts, strategies, and application. Pearson/ Merrill/Prentice Hall Upper Saddle River, NJ.

Dyrbye, L., Cumyn, A., Day, H., \& Heflin, M. (2009). A qualitative study of physicians' experiences with online learning in a masters degree program: Benefits, challenges, and proposed solutions. Medical Teacher, 31(2), e40-e46. https://doi.org/10.1080/01421590802366129

Fish, L. A. (2016). A Preliminary Study of Changes in Online Graduate Business Student Perceptions Over a Course. Business Education Innovation Journal, 8(2).

Garland, M. R. (1993). Student perceptions of the situational, institutional, dispositional and epistemological barriers to persistence. Distance Education, 14(2), 181-198.

Gerbing, D. W., \& Anderson, J. (1988). An updated paradigm for scale development incorporating unidimensionality and its assessment. Journal of marketing research, 25(2), 186-192.

[Record \#79 is using a reference type undefined in this output style.]

Henderikx, M., Kreijns, K., Castaño Muñoz, J., \& Kalz, M. (2019). Factors influencing the pursuit of personal learning goals in MOOCs. Distance Education, 40(2), 187-204. https://doi.org/10.1080 /01587919.2019.1600364

Horspool, A., \& Lange, C. (2012). Applying the scholarship of teaching and learning: student perceptions, behaviours and success online and face-to-face. Assessment \& Evaluation in Higher Education, 37(1), 73-88. https://doi.org/10.1080/02602938.2010.496532

Hurmerinta-Peltomaki, L., \& Nummela, N. (2006). Mixed methods in international business research: A value-added perspective. Management International Review, 46(4), 439-459. https://doi.org/ https://doi.org/10.1007/s11575-006-0100-z

Khalil, H., \& Ebner, M. (2014). MOOCs completion rates and possible methods to improve retention-A literature review. EdMedia+ innovate learning,

Klein, J. T. (2004). Prospects for transdisciplinarity. Future, 36(4), 515-526.

Kokko, T., Pesonen, H., Kontu, E., \& Pirttimaa, R. (2015). Why Study Online in Upper Secondary School? Qualitative Analysis of Online Learning Experiences. Human Technology: An Interdisciplinary Journal on Humans in ICT Environments, 11, 57-70. https://doi.org/10.17011/ht/urn.201505061740

Landrum, B., Bannister, J., Garza, G., \& Rhame, S. (2020). A class of one: Students' satisfaction with online learning. Journal of Education for Business, 1-7. https://doi.org/10.1080/08832323.2020.1757592

Loveland, K. A., \& Loveland, J. P. (2003). Student Evaluations of Online Classes versus On-Campus Classes. Journal of Business Economics Research, 1(4). https://doi.org/10.19030/jber.v1i4.2993

Lowenthal, P., Bauer, C., \& Chen, K.-Z. (2015). Student Perceptions of Online Learning: An Analysis of Online Course Evaluations. American Journal of Distance Education, 29(2), 85-97. https://doi.org $/ 10.1080 / 08923647.2015 .1023621$

Mbuva, J. M. (2014). Online education: Progress and prospects. Journal of Business Educational Leadership, 5(1), 91. 
Moll, M. (1998). No more teachers, no more schools: information technology and the "deschooled" society. Technology in society, 20(3), 357-369. https://doi.org/10.1016/S0160-791X(98)00021-9

Muilenburg, L., \& Berge, Z. L. (2001). Barriers to distance education: A factor-analytic study. American Journal of Distance Education, 15(2), 7-22. https://doi.org/10.1080/08923640109527081

Muilenburg, L. Y., \& Berge, Z. L. (2005). Student barriers to online learning: A factor analytic study. Distance Education, 26(1), 29-48. https://doi.org/10.1080/01587910500081269

Nguyen, S. H. (2020). 92 Universities in Vietnam Applying Online Education https://vtc.vn/92-truongdai-hoc-ap-dung-hinh-thuc-day-truc-tuyen-ar535639.html

Noble, D. F. (1998). Digital diploma mills: The automation of higher education. Science as culture, 7(3), 355-368. https://doi.org/10.5210/fm.v3i1.569

Nunnally, J. C., \& Bernstein, C. (1994). Psychometric theory. New York.

O'Cathain, A., Murphy, E., \& Nicholl, J. (2010). Three techniques for integrating data in mixed methods studies. Bmj, 341. https://doi.org/10.1136/bmj.c4587

Platt, C. A., Raile, A., \& Yu, N. (2014). Virtually the same? Student perceptions of the equivalence of online classes vs. face-to-face classes. Journal of Online Learning and Teaching, 10, 489-494.

Sargeant, J., Curran, V., Jarvis-Selinger, S., Ferrier, S., Allen, M., Kirby, F., \& Ho, K. (2004). Interactive online continuing medical education: Physicians' perceptions and experiences. Journal of Continuing Education in the Health Professions, 24(4), 227-236. https://doi.org/10.1002/chp.1340240406

Schilke, R. A. (2001). A case study of attrition in web-based instruction for adults: Updating Garland's model of barriers to persistence in distance education. Northern Illinois University.

UNESCO. (2020). Education: From disruption to recovery. Retrieved March 6, 2020 from https://en.unesco. org/covid19/educationresponse

Urdan, T., Weggen, C., \& Cornelia, C. (2000). Corporate e-Learning: Exploring a New Frontier, March 2000. Research Paper from WR.

Waldman, L., Perreault, H., Alexander, M., \& Zhao, J. (2009). Comparing the perceptions of online learning between students with experience and those new to online learning. Information Technology, Learning, Performance Journal, 25(2), 20.

Wyatt, G. (2005). Satisfaction, academic rigor and interaction: Perceptions of online instruction. Education, 125(3). 